\section{Book Reviews/Revue de livres}

Balancing Act; Environmental Issues

in Forestry. Hamish Kimmins, UBC

Press, Vancouver. ISBN 0-7748-0435

-1 (hardcover) 0-7748-0426-2 (paperback), 1992. Hardcover available in December, paperback $\$ 29.95$

Dr. Kimmins has written a comprehensive account of what forestry is all about, and the relationships between environment and forest management. It is as balanced as the title indicates and as lucid as any lay reader might want. Each chapter has an introductory overview and a concluding summary but, despite this, the book is not written in textbook style.

The professional forester should not learn much that is new but will find a usefully-comprehensive refresher; the timber harvester will find broadened horizons and some justified criticisms; the 'deep green' environmentalists will be disappointed that some of their favoureds shibboleths are denied; and the lay reader will come to comprehend the complexities of forests and the folly of simplistic generalisations.

Despite its many qualities the book is not perfect: the illustrations are no more than adequate; there is repetition which, though reflecting the interrelatedness of forestry topics, could have been reduced by rigorous editing; surprisingly little appears about what ecological lessons are being learned from the aftermath of the Mt. St. Helens eruption; and there are a few stylistic lapses - adjectives used as adverbs, an occasional split infinitive, New Hamphire is NOT in western US and what is meant by "over-ephemeral". These are not serious flaws nor do they detract from the undoubted merits of the book. Perhaps they can be corrected in a second edition. I hope one will be required because this is a valuable contribution to thoughtful discussion of forestry management issues.

Dr. Kimmins has combined scholarly comprehension with nontechnical readability, and is much more informative and useful than Hammond's contemporary "Seeing the Forest Among the Trees". Though glossier and better illustrated, Hammond's book is an unfortunately biased polemic by comparison. Anyone concerned with understanding forests and forestry, or planning to enter the "forests $x$ environment" debate will be well advised to study this book carefully.

\section{R.M. Strang}

Wildlife Research and Management in the National Parks. R. Gerald Wright, University of Illinois Press, Urbana and Chicago, 224 p., 1992, \$, ISBN 0-252-01824-9.

"As park environments are increasingly threatened by growing numbers of visitors, outside land-use changes, and pollution, it is more important than ever that scientific knowledge, administrative willingness, and public support combine to help create the policies necessary for appropriate management and protection of park resources". This is the author's incentive for "tracing the history of wildlife management in the US national parks, bringing together a diversity of literature and previously unpublished information".

Wright begins with an overview of the historical background of the US National Park Service, their science program administration, and resource management policies. The following five chapters detail specific historical anecdotes and policy development concerning animal control, ungulate management, alien species management, bear management, and wolf reintroduction. Human-wildlife interactions and conflicts are reviewed and discussed. The classification scheme is explained for national preserves, where resource extraction is permitted, unlike national parks. Wright ends his book with a summary of scientific research efforts in the National Park Service, and his recommendations for effective and long-term research and management plans. This section contains some of the best writing and is equally relevant to the Canadian national parks system.

Overall, this book is well written and organized with often fascinating glimpses of politics, parks, and wildlife, but is unlikely to be of interest to a general audience. The topics are comprehensively examined and readers will suffer somewhat from frequent overlap among chapters. For those wishing to become more informed about wildlife research and resource management policies within parks, this is a useful source. Wright's book will appeal most to land managers and conservationists directly interested in park systems.

\section{Julie Towers Extension Specialist-Wildlife N.S. Department of Natural Resources}

Vanishing Rain Forests: The Ecological Transition in Malaysia. S. Robert Aiken and Colin H. Leigh, Oxford Science Publications, Clarendon Press, Oxford, 194 p., 1992, \$108.00, ISBN 0-19-854242-9.

The focus of this book is "the human interaction with the forests of Malaysia". More bluntly, the book is about the destruction of rain forests in Malaysia. Four interrelated themes are addressed:

- description of rain forest formations and their remarkable diversity of flora and fauna,

- outline of processes and policies resulting in anthropogenic forest change,

- environmental, biological, and human consequences of change, and

- description of measures to conserve the region's forests, natural systems and wildlife.

The book is arranged in five chapters (Wither tropical rain forests?; The rain forests of Malaysia; Resource utilization and forest conversion - processes and policies; The human impact; and Conservation - towards a sustainable future) and an Epilogue. Useful chapter-by-chapter notes are sandwiched between the Epilogue and 30 pages of References.

The problem and scale of destruction of tropical rain forests, particularly in Malaysia, are well documented and vividly portrayed in this book. The preliminary overview of rain forests in general and of those that occur in Malaysia is clear and enlightening. The role of rainfall in supporting such forests is generally understood, but the variation and intensity are not always appreciated. Most areas of Malaysia receive more than $2000 \mathrm{~mm}$ of rain annually, some areas more than $3500 \mathrm{~mm}$ (11.5 feet!); and 24-hour totals of $610 \mathrm{~mm}$ (24 inches) are not unknown. Yet occasional droughts occur.

The richness of the rain forest biota is illustrated by the number of plant species native to Peninsular Malaysia. In 
an area of only about $132,000 \mathrm{~km}^{2}$, there are about 8000 species of flowering plants, including 2600 tree species. In contrast, only about 700 species of trees are native to the whole of North America.

The rain forests of Malaysia belong to the West Malesian province of the Malesian floristic region of southeast Asia. West Malesia includes the Malay Peninsula, Borneo, Sumatra, and the Phillippines. This province is characterized by the abundance of dipterocarps, trees and shrubs which derive their name from the large sepalderived wings attached to fruits. The wealth of biodiversity in these forests is hard to appreciate for anyone who has not had the good fortune to experience it firsthand. There are, for instance, five times as many species of oak on the slopes of Mount Kinabalu in Sabah (part of Eastern Malaysia, on the island of Borneo) as in the whole of Europe, together with 400 species of ferns and 800 species of orchids.

Of particular interest is the heath forest formation, which replaces the evergreen lowland rain forest in parts of the Malesian botanical region, most extensively in Sarawak. Heath forest is usually found on free-draining podzolic soils. A distinctive feature of many of these forests is the presence of the conifers Podocarpus and Dacrydium. Two opposing theories have been advanced to explain the distinctive structure and xeromorphic physiognomy of the heath forest: periodic drought, and nutrient deficiency. This brings to mind similar debates as to the relative strengths of the water- vs. nutrient-constraints in connection with explanations of growth "check" in temperate and boreal regions.

Anthropogenic forest change in Malaysia spans several millenia, but it was not until the 19th Century that there was any appreciable increase in the pace or scale of such change. The introduction of rubber cultivation was the first major impact on the rain forest in the western lowlands of the Peninsula, but the rate of forest destruction increased dramatically subsequent to Malaysia's independence in 1957.

Aiken and Leigh give an excellent exposition of the problem. It reads well and convincingly. The only disappointment, perhaps inevitable, is that the authors could offer no practical solution to the problem. Short of adopting Spike
Milligan's remedy of population reduction, there seems little hope of saving the rain forests.

The few minor flaws, e.g., the number of dipterocarps mentioned in the text ("269 species") does not quite jibe with the number given in Figure 2.1, and the poor delineation of forest formations in Figure 2.2, detract little from the work. Particular strengths include referencing to page numbers in cited works, and each chapter concludes with a particularly good summation of the chapter's content. The use of parenthetic amplification of subject matter is excellent. However, the price of the book will restrict sales to a few of the more affluent libraries.

I cannot resist expressing one final thought: if the book were to be translated into German, what a word would be produced by the phrase "decentralized, small-scale, sustainable, peopleoriented, forest-based local industries"' (p. 146)!

\section{R.F. Sutton}

Advances in The Physiology of Poplar. Wang Shan-sheng, Wang Shiji and Pei Bao-hua (Eds.), Publishing House of Beijing Agricultural University, Beijing, China, 386 p., 1990.

The book represents an effort to integrate recently achieved knowledge on hybrid poplar's physiology, mensuration and silviculture, within The Populus and Salix Programme of The Research Institute of Forestry, one of the seven institutes that constitute The Chinese Academy of Forestry in Beijing.

In China, hybrid poplar is a ubiquitous species in both the rural and city landscape. A number of clones were introduced from Europe after The Second World War and have been multiplied without much varietal control since. Oblivious to the requirements of intensive poplar culture, as developed in Western Europe, the Chinese farmers soon realized the multiple potential of hybrid poplar, and quickly learned how to propagate it. Therefore, hybrid poplars have been employed extensively for: shelterbelts in arid zones, specialized building material (especially for roofing), renewable fuel and fodder, as well as in the fight against erosion. The tremendous expansion of hybrid poplar from the countryside to the finely mani- cured Chinese landscape of the new and modern neighbourhoods of Beijing, has greatly aroused the interest of the government for this resource.

Before long, the Chinese forest researchers realized that their country had a rich genetic base for hybridization and selection, a favourable climatic environment, a lot of suitable planting sites, as well as a great economic need for industrial-quality poplar logs (veneer for furniture and match industries). This is how the Populus and Salix Programme of The Research Institute of Forestry, one of the major national programs in forestry and environment, was born. Subsequently, with some foreign assistance consisting of newer clonal material for afforestation, research equipment and computers, as well as consultants, a number of research directions have been pursued by the Chinese scientists, namely: testing of a large number of clones, hybridization work followed by selection of new clones, physiological research related to early testing, spacing and pruning studies, as well as mensuration and wood quality investigations to define the dimensional and technological characteristics of the main clones. The rapid progress of Chinese foresters and farmer's organizations in the area of poplar and willow culture is largely the result of their ability to develop widespread international contacts and apply and quickly adapt the new knowledge to their conditions, both in research and practical silviculture.

This book is considerably more than its title would reveal. It is organized into 4 sections covering the following main areas: (i) water relations - 113 p., (ii) mineral nutrition - 126 p., (iii) photosynthesis -72 p., and (iv) growth and development -74 p. Almost all of the individual papers have half page English abstracts, and are less than 10 pages each. They cover a wide range of topics and scientific content.

Among the 18 papers of the section devoted to water relations one finds both "classic" research on the transpiration process in a controlled environment as well as "modern" studies of ecology, such as the water stress influence on growth of poplar stands. Notable contributions belong to Wang Shi-ji (growth rhythm and changes of the water regime, water supply influences on wood quality), and Liu Feng-jue (water relations of deeply 
planted poplars; relationship between water supply and growth in poplar plantations).

The 20 papers that form the section on mineral nutrition present various results of laboratory and field experiments related to nutrition. The majority of papers are devoted to the effects of additional nitrogen supply on growth, studied mostly on clones already accepted in China for large scale plantations.

The next 10 papers deal with photosynthesis. This section reveals that Chinese researchers are attempting to effectively use this physiological parameter for the early testing of hybrid poplars. The research is based on modern techniques and equipment and the object of investigations are either new Chinese-bred selections or modern West-European clones, with good potential for large scale, industrial plantations in China. The most remarkable contributions in this section belong to Yin Wei-lun (use of photosynthesis and respiration in early testing) and Liu Ya-rong and other (photosynthetic studies correlated with growth for four important poplar hybrids).

The last section, composed of 11 papers, presents original research on growth and development. Worthy of notice here again is Wang Shi-ji (studies on root primordia and formation of adventitious roots at poplar and willow) along with Zheng Jun-bao (hormones and the rooting process).

In general, judging from the English abstracts, the book appears well balanced and particularly useful for the Chinese scientist intent on specializing in the physiology or silviculture of Salicaceae species. Quite a few papers included in this book, if expanded and thoroughly translated into English by a specialist having a good command of the terminology in both languages, would result in publishable articles for the peer reviewed scientific journals covering: physiology, soil science and silviculture, thus making the Chinese contributions available to the international scientific community.

There are still a few weak areas in this book. There is some non-consistent writing of Latin names of parent species. Furthermore, some of the papers have no English abstracts at all, and therefore cannot be judged, except from the translated title.

\section{Forestry is not about trees, it is about people and it is about trees only insofar as trees can serve the needs of people}

Jack Westoby

Advances in The Physiology of Poplar is well above the level of common poplar growers, but it would be particularly useful to professionals and scientists. Instead of finding information about a well established growing technology, as one can get from a technical handbook, the professional will find results of alternate technologies tested for various regions of China. In planning large-scale poplar plantations on diverse site conditions, such information may allow more room for interpretation and adaptation to local conditions than the prescriptions of a technical handbook.

The literature devoted to poplar and willow in China still has some gaps. Firstly, there is a great need for a medium-level handbook for poplar growers and peasants in farmer's associations who, in the new economic environment, regard poplar as a lucrative cash crop. Clear and correct information for farmers with respect to: proper nursery techniques, stand establishment, individual tree care as applied to poplar in order to obtain industrialquality logs, fertilization and harvesting is lacking. This book does not provide specific guidance but rather lays a good scientific foundation for it, awaiting a compiler to produce a medium-level handbook. Secondly, the poplar and willow literature still requires new books on some major issues, such as: site selection and potential (site requirements and limitations, climatic potential for poplar culture in various provinces, phenology and other ecological aspects), poplar and willow silviculture (site preparation, stand establishment, spacing vs. growth, pruning vs. $\log$ quality, thinning schedules, har- vesting), poplar and willow on degraded lands, role of poplar and willow in flood control (along the major Chinese rivers and their tributaries), poplars in shelterbelts, genetics and selection of poplar and willows (inventory of indigenous taxa and their potential for hybridization), growth and yield (productivity, environmental control of growth, spacing influence on stem form), protection and pathology (biology of insects and diseases of risk), wood technology and industrialization (technological traits of the wood of main clones and particulars of Chinese woodworking industry).

The great diversity of ecological conditions, the immensity of the country, its stringent constraints with respect to land uses, the particularities of its industrial requirements and the large number of professionals, technicians and farmers involved in poplar culture, as well as the yet not fully tapped potential of Salicaceae species in China, all justify true monographs on these subjects. In this context, this book satisfies this need mainly in the area of growth physiology.

\section{C.S. Papadopol, Ph.D. Research Scientist, Forest Ecophysiology and Intensive Silviculture Ontario Forest Research Institute, Sault Ste. Marie, Ontario}

Herbert Richardson. Paul Masterson. Fitzhenry \& Whiteside, Richmond Hill, 64 p. + illus. 1992. ISBN 0-88902339-5 Price 10.95, available to CIF/ IFC members for 7.00. Order through CIF/IFC National Office. 
This book is the most recent one in the series, "The Canadians"'. It is of particular interest to foresters not only because Richardson was a forester, but also because of his role in the Ontario conservation movement from the 1930's to his death in 1971, and the part he played in the Canadian Society of Forest Engineers (now CIF) as Editor of The Forestry Chronicle.

The book has five chapters which, in chronological sequence, set the historical context for the biography of Richardson and give the reader a sense of some of the societal and political forces at work related to forestry during his lifetime. Chapter one is a brief history of the early exploitation of eastern Canada's forests. Chapter two is an account of the roots of the Richardson family. Chapter three is devoted to a brief history of forestry and the conservation movement from the late 1800's to 1960 , the beginnings of the Canadian Forestry Association, professional foresters, and the founding of the Canadian Society of Forest Engineers. In a book meant for the general public Masterson is to be commended for presenting, albeit briefly, this account of the beginnings of professional forestry and recognizing the foresters involved.

Chapter four deals with Richardson's major involvement with the Boy Scouts of Canada and his influence and activity in promoting forestry and conservation with the young. The final chapter focusses on the conservation movement in southern Ontario, particularly the development of conservation authorities after World War II and the significant role that Richardson played in it. Today, when in many quarters the notion of community forests is being touted as an innovation it is useful to reflect on the long history of community forests in Ontario beginning with the agreement forests of the 1920's through to present day conservation authorities.

The role of foresters and the positive contributions that they have made in Canada to conservation since the early 1900 's is little known, although countless thousands of urban dwellers in eastern Canada enjoy the benefits of their work in the forests they helped create. Masterson's book goes some way to give the general reader a sense of what has been accomplished and who was responsible. It is to be hoped that this book may whet the appetites of

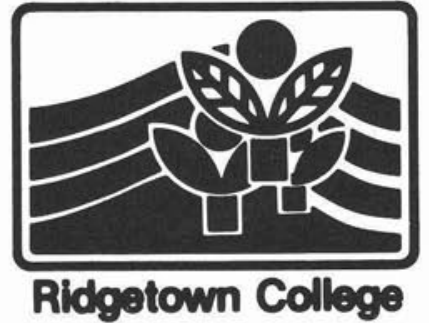

$$
\begin{gathered}
\text { A CIF/IFC } \\
\begin{array}{c}
\text { Corporate Sustaining } \\
\text { Member }
\end{array}
\end{gathered}
$$

readers and future writers for more indepth accounts of foresters and their contributions to Canada.

\section{K.A. Armson, R.P.F.}

Young Men and Fire. A True Story of The Mann Gulch Fire. Norman MacLean. Illustrated. 301 Pages. University of Chicago Press. $\$ 19.95$ U.S. 5801 South Ellis Ave. Chicago, Illinois 60637. ISBN 0-226-50061-6.

Norman MacLean's "'Young Men and Fire" is a detailed reconstruction of a disastrous fire in western Montana in August 1949. You may recognize the author, he also wrote $A$ River Runs Through It which is currently a Robert Redford movie starring Brad Pitt, Craig Sheffer and Emily Lloyd.

Young Men and Fire is MacLean's attempt to review the sequence of events that led to the deaths of twelve young U.S. Forest Service Smoke Jumpers and to apply current expertise in fire science to explain what had happened.

MacLean retraces the known events of the fire, takes the survivors back to the site to painstakingly reconstruct the timing and sequence of events and looks at the controversy that surrounded the fire. The book includes maps and photographs which help the reader to follow the sequence of events, while bringing home the intensity of the tragedy. Some of the controversy, which drew the attention of Life Magazine, was the focus of a Forest Service inquiry and prompted some of the parents of the victims to file law suits, was the first known use of an "escape fire". The crew foreman, R. Wagner Dodge, felt that his crew of fourteen could not outrun the fire which was moving up a steep slope in very dry, long grass and being pushed by strong winds. He lit an "escape fire" in unburned grass, waited a few seconds and lay down in the ashes, ordering his men to join him. The men must have thought that Dodge had lost his mind and chose instead to race the fire to the top of the ridge. Only two of the fourteen won the race and in the aftermath, many believed that the escape fire caused the death of at least some of the men.

MacLean wanted to provide answers to many questions about the fire so that people could learn from the tragedy. $\mathrm{He}$ looks at what caused a small, containable lightning fire to blow up. He explores how two smoke jumpers were able to reach the top of the ridge and survive. He determines if Dodge was wrong to have built his escape fire.

MacLean is able to recreate the tension and foreboding of the tragedy years after the event when he gets into fine details of fuel types, rate of spread and other computer modelling details he tends to go on at length and become somewhat tedious. Perhaps fire science people will not agree, but I found the retelling and investigation of the fire much more fast paced and interesting. It may be likely that fire people will enjoy the fine details of reconstructing a tragedy from 1949 with all the science, computer models and knowledge of the late 1980's. It reminded me of solving a murder mystery of long ago with the help of modern science.

Young Men and Fire has mystery, intrigue and danger enough for any reader. Certainly anyone who, like myself has ever worked on a fire will enjoy this sad and compelling true story. Those involved in fire science will certainly delight in following the challenge that MacLean put to the researchers at the fire lab in Missoula, Montana to recreate and detail sequence of a fire from almost forty years earlier. And for the person with no experience or connection with forestry or forest fires I think it would provide interesting and educational reading. MacLean's writing style combines poetry and scientific objectivity and he is a great storyteller. I plan to read his other works.

C.A. Lee, R.P.F. Executive Director Canadian Institute of Forestry 